\title{
Mental Health, Wellness, and Childhood Overweight/Obesity
}

\author{
Shelly Russell-Mayhew, ${ }^{1}$ Gail McVey, ${ }^{2}$ Angela Bardick, ${ }^{1}$ and Alana Ireland ${ }^{1}$ \\ ${ }^{1}$ Educational Studies in Counselling Psychology, Faculty of Education, University of Calgary, \\ EDT 318, 2500 University Drive NW, Calgary, AB, Canada T2N 1N4 \\ ${ }^{2}$ Community Health Systems Resource Group, The Hospital for Sick Children, \\ 555 University Avenue, Toronto, ON, Canada M5G 1 X8
}

Correspondence should be addressed to Shelly Russell-Mayhew, shelly.russell-mayhew@ucalgary.ca

Received 14 February 2012; Revised 26 April 2012; Accepted 30 April 2012

Academic Editor: Devin Mann

Copyright (C) 2012 Shelly Russell-Mayhew et al. This is an open access article distributed under the Creative Commons Attribution License, which permits unrestricted use, distribution, and reproduction in any medium, provided the original work is properly cited.

\begin{abstract}
Childhood obesity is a growing concern, and while progress has been made to understand the association between multiple biological factors (i.e., genetics, nutrition, exercise etc.), little is known about the relationship between mental health and childhood obesity. In this paper, we offer a review of current evidence about the association between mental health and childhood obesity. A systematic literature search of peer-reviewed, English-language studies published between January 2000 and January 2011 was undertaken and resulted in 759 unique records, of which 345 full-text articles were retrieved and 131 articles were included. A theoretical model is proposed to organize the paper and reflect the current state of the literature and includes psychological factors (i.e., depression and anxiety, self-esteem, body dissatisfaction, eating disordered symptoms, and emotional problems); psychosocial mediating variables (i.e., weight-based teasing and concern about weight and shape), and wellness factors (i.e., quality of life and resiliency/protective factors). We conclude with a number of recommendations to support the creation of solutions to the rise in childhood obesity rates that do not further marginalize overweight and obese children and youth and that can potentially improve the well-being of all children and youth regardless of their weight status.
\end{abstract}

\section{Introduction}

Obesity, a state of excess body fat, is commonly assessed using the body mass index (BMI), a ratio of weight $(\mathrm{kg})$ to height $\left(\mathrm{m}^{2}\right)$, and a BMI of over $30 \mathrm{~kg} / \mathrm{m}^{2}$ is considered obese [1]. In children, the BMI is plotted on growth charts for interpretation relative to a healthy reference population and percentiles are then used to define obese ( $>95$ th percentile) and overweight ( $>85$ percentile) [2]. The prevalence of obesity and overweight among children has shown dramatic increases over the past 25 years [3]. While recent analyses suggest that rising childhood obesity rates may be leveling off [4], more than $1 / 3$ of children under the age of 11 in Canada are either overweight or obese [5-7]. Most efforts to "reverse the epidemic of obesity" [8, page 717] have focused on nutrition or food intake and physical activity levels with the measure of success being decreased weight or BMI. To date, the rate of efficacy of this prevention approach is $21 \%$ [9] suggesting the need to search for additional ways to intervene. One area that has yet to receive meaningful examination is how mental health may influence or be influenced by efforts at preventing obesity. The purpose of the present paper is to provide an overview of research linking mental health indices to obesity and to challenge the current notion that prevention should focus solely on nutrition, weight, and physical activity.

\section{Literature Review Criteria}

A systematic literature search of peer-reviewed, Englishlanguage studies published between January 2000 and January 2011 was undertaken on computerized psychological, social science, medical, and education databases including Psychology and Behavioral Sciences Collection, PsycINFO, MEDLINE, Cumulative Index to Nursing and Allied Health Literature (CINAHL), Educational Resources Information Centre (ERIC), Cochrane Database of Systematic Reviews (DSR), and Cochrane Central Register of Controlled Trials 
(CCTR). Keyword combinations are listed in Table 1. Research on the physical health consequences of overweight or obesity was excluded; as were research articles that took up issues of measurement of overweight/obesity. Because this paper focused specifically on mental health and wellness in relation to the prevention of childhood obesity, some of the contextual (i.e., media, family), economic (i.e., food and diet industries), environmental (i.e., poverty), biological (i.e., metabolism), behavioural (i.e., sleep), and cultural (i.e., ethnicity) correlates of obesity are not reviewed.

In total, 759 unique records were obtained from the searches, 345 full-text articles were retrieved, and 131 articles were included in the document.

\section{Overview}

Obesity is not a psychological disorder, but some researchers and clinicians argue that it should be considered a mental or behavioural issue [10]. As it currently stands, obesity remains a medical condition, and, perhaps for this reason, research has focused neither on understanding the psychological impact of living with obesity nor the influence of mental health on the development of obesity. Although mental health professionals have been involved in the treatment and/or prevention of obesity, it is implicitly assumed that weight loss or the prevention of weight gain, respectively, will solve the psychological/emotional issues than may accompany excess weight which may not be the case. It should be noted that the treatment of pediatric obesity may vary with age particularly as approaches to childhood obesity migrate to a more integrated shared-responsibility model of service delivery [11]. The focus of this paper is on psychosocial constructs as they relate to influencing the prevention of childhood obesity and as such experiences from clinical settings or evidence of successful family-based treatment approaches are beyond the scope of this paper.

Some psychosocial factors have been identified and studied; however, research usually examines each construct independently with little consideration for the relationship between excess weight and a broad range of psychosocial constructs concurrently [12]. Research has not yet uncovered a clear model to elucidate these relationships. It is unclear to what extent psychosocial issues coexist in overweight/obese children or whether the strength or nature of the association changes with increasing weight [12]. A recent review by Wardle and Cooke [13] included 53 studies examining the relationship between obesity and psychosocial factors distinguishing clinical and community samples. Evidence for a causal or predictive relationship between obesity and mental health is inconclusive at best. The direction of the relationship between mental health and obesity certainly remains unclear as most of the studies are cross-sectional (e.g., $[13,14])$. Of the limited longitudinal data available, some studies find evidence that mental distress predicts overweight or weight gain (e.g., $[15,16]$ ), others find no associations between weight status and mental health (e.g., $[17,18])$, and one found that behavioural issues predicted becoming overweight [19]. Despite these associations, it is clear that not all overweight/obese children experience psychosocial issues. In fact, some research suggests that concern about weight and shape (not actual weight) [2022] and/or being the victim of weight-based teasing [23] may in fact account for any individual differences in psychosocial outcomes [12].

Despite the inconsistencies and uncertainties arising from the current evidence base, there appears to be some consensus that obesity is a potential risk factor with regard to children's and adolescents' psychological and emotional well-being and that vigilance for potential difficulties is a responsible approach to take [23, page 193].

\section{Proposed Model}

Given the lack of a clear model that elucidates the relationship between mental health and overweight/obesity, we propose a theoretical model (see Figure 1) (This figure was expanded and adapted from figures shown by Rebecca Puhl at the Canadian Obesity Network 1st Canadian Summit on Weight Bias and Discrimination). Main concepts in this model include psychological factors, mediating variables, and wellness factors. Most research has not examined these psychosocial factors in one study, and this paper aims to look at these factors together.

\section{Psychological Factors}

5.1. Depression and Anxiety. A recent review concluded that the majority of studies find a prospective relationship between eating disturbances and depression [24]. However, this relationship is not unidirectional; depression may be both a cause and a consequence of obesity [25]. Additionally, in a clinical sample of obese adolescents, a higher lifetime prevalence of anxiety disorders was reported compared to nonobese controls [26], although some studies demonstrate no significant relationship between increased BMI and increased anxiety symptoms [27]. Thus, the relationship between obesity and anxiety may not be unidirectional and is certainly not conclusive.

5.2. Self-Esteem. Research findings comparing overweight/ obese children with normal-weight children in regards to self-esteem have been mixed [28]. Some studies find that obese children have lower self-esteem [29] while others do not $[21,30]$. There is some consensus in the literature that the global approach to self-esteem measurement with children who are overweight/obese is misleading as the physical and social domains of self-esteem seem to be where these children are most vulnerable [31].

5.3. Body Dissatisfaction. Research has consistently found that body satisfaction is higher in males than females at all ages [32]. Gender differences may reflect the Westernized cultural ideals of beauty in that thinness is the only culturally defined ideal for females, while males are encouraged to be both lean and muscular. Thus, there is a linear relationship between body dissatisfaction and increasing BMI for girls; while for boys a U-shaped relationship suggests that boys 
TABLE 1: Search terms used.

\begin{tabular}{|c|c|c|c|}
\hline Population & Intervention & Outcome & Type of study \\
\hline $\begin{array}{l}\text { Child } \\
\text { Preschool } \\
\text { Adolescent } \\
\text { Pediatrics } \\
\text { Young people } \\
\text { High school }\end{array}$ & $\begin{array}{l}\text { Health policy } \\
\text { Health promotion } \\
\text { Health education }\end{array}$ & $\begin{array}{l}\text { (a) Overweight } \\
\text { Obesity } \\
\text { Body weight } \\
\text { Body mass index } \\
\text { Body image } \\
\text { (b) Mental health } \\
\text { Depression } \\
\text { Anxiety } \\
\text { Psychological } \\
\text { (c) Wellness } \\
\text { Adaptation } \\
\text { Resilience } \\
\text { Quality of life } \\
\text { Lifestyle } \\
\text { (d) Social stigma } \\
\text { Prejudice } \\
\text { Teasing } \\
\text { Bullying } \\
\text { Peer victimization }\end{array}$ & $\begin{array}{l}\text { Excluding: } \\
\text { editorials } \\
\text { comments }\end{array}$ \\
\hline
\end{tabular}

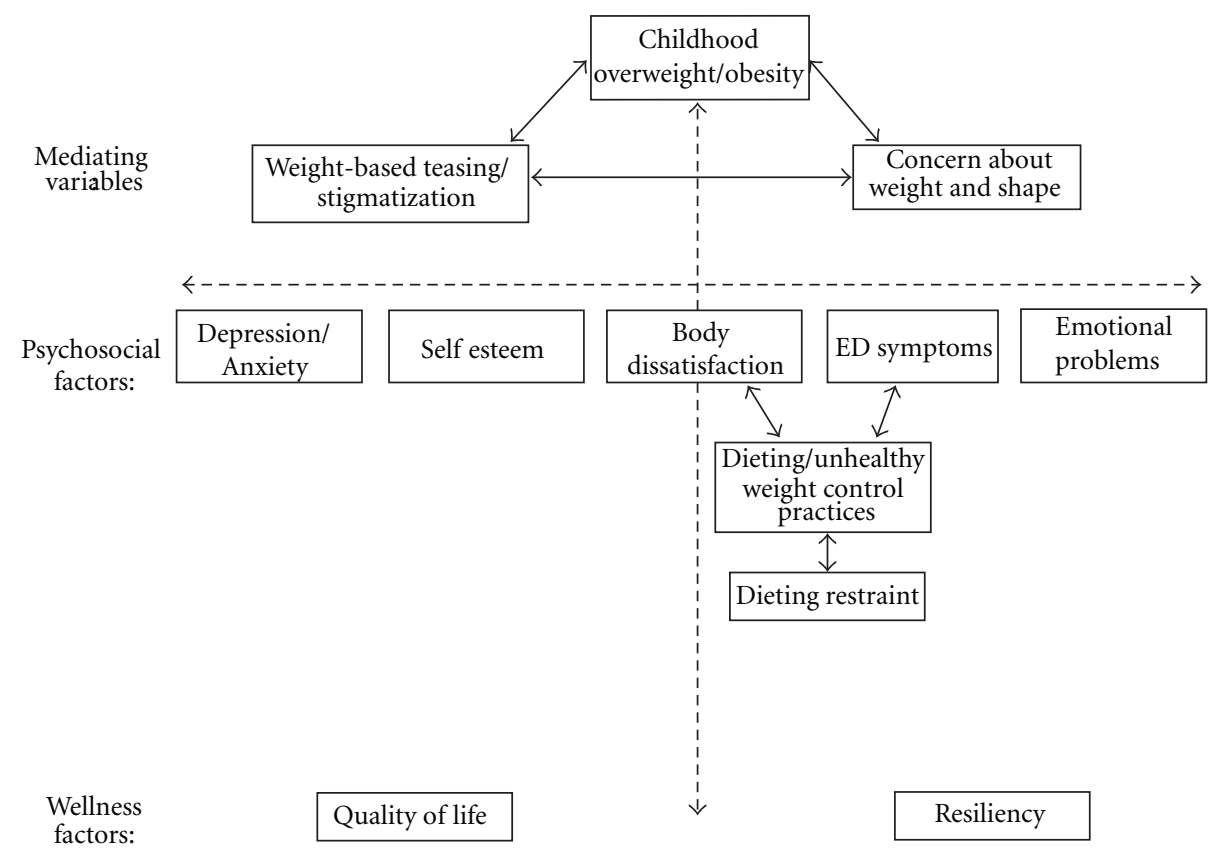

FIgure 1: Proposed model.

with BMIs at the low and high extremes experience high levels of body dissatisfaction $[33,34]$.

5.3.1. Dieting/Unhealthy Weight Control Practices. A less well-known public health issue that elevates risk for obesity is the evidence of increased frequencies of unhealthy dieting behaviours among young people. Restrictive dieting is linked to both disordered eating/eating disorders and weight gain/obesity $[35,36]$. Unhealthy weight control behaviours were reported by $57 \%$ of girls and $33 \%$ of boys, and extremely 
unhealthy behaviours were reported by $12 \%$ girls and $5 \%$ of boys among 4,476 adolescents in public schools in Minnesota [37].

5.3.2. Dietary Restraint. Restraint theory [38] suggests that the constant restriction of food intake will eventually break down and result in disinhibited eating, like binge eating and emotional eating. This pattern can lead to decreased sensitivity of the body's natural hunger and satiety cues and an overreliance of contextual cues for eating [39]. Dietary restraint is associated with obesity (cross-sectional data; $[40])$ and predictive of future weight gain in youth $[35,41]$.

5.4. Eating Disorder Symptoms. Traits associated with eating disorders appear to be common in adolescent obese populations, particularly for girls [42]. A number of studies have shown higher prevalence of eating-related pathology (i.e., binge eating episodes, drive for thinness, impulse regulation) in obese children/youth $[43,44]$.

5.5. Emotional Problems. In one of the few studies to investigate the psychological impact of being overweight/obese in children, Cornette [45] reviewed 10 published studies over a 10-year period (1995-2005) with sample sizes greater than 50 and concluded that all participants reported some level of psychosocial impact as a result of their weight status. Being younger, female, and with an increased perceived lack of control over eating seemed to heighten the psychosocial consequences.

\section{Mediating Variables}

Two mediating factors emerged for understanding how overweight/obesity impacts psychosocial health and wellness and vice versa: (a) weight-based stigmatization and teasing and (b) weight and shape concerns.

6.1. Weight-Based Stigmatization and Teasing. Weight-based stigmatization is defined as "negative weight-related attitudes and beliefs that are manifested through stereotypes, bias, rejection, and prejudice toward children and adolescents because they are overweight or obese" [45, page 558]. Given the increase in the rate of childhood overweight/obesity, some people [46] have hypothesized simply by virtue of exposure that stigmatization or bias would have decreased. On the contrary, negative views of obese children are even higher than 40 years ago $[10,47]$. The visible nature of obesity (i.e., it is not something that you can hide) as well as the assumption that obesity can be controlled (i.e., eat less and move more) is important determinants of weight bias. Obesity is considered to be one of the "most stigmatizing and least socially acceptable conditions in childhood" [30, page 1818]. The effects of this weight bias can be seen even years later. "Childhood obesity is related to fewer years of education, lower family income, higher poverty rates, and lower marriage rates in later young adulthood" [48]. Puhl and Latner [49] completed a comprehensive literature review on childhood weight-based stigmatization and found that children demonstrate weight bias by associating obesity with a number of undesirable traits and preferring to associate with nonobese peers. Children with more negative attitudes towards weight more likely rate an obese peer negatively and tease and bully children who appear overweight, with few cultural differences [49].

Experiences of weight-based teasing have been hypothesized as a mediating variable in the development and maintenance of overweight and obesity [50]. Not only do overweight/obese children have increased risk of experiencing significant victimization, but peer victimization has been linked to negative psychosocial and health outcomes [51] as well. "Peer victimization refers to the experience of overt (e.g., pushing, hitting, kicking) or relational (e.g., gossiping, teasing, ignoring, excluding) forms of aggression as perpetuated by an individual or group of peers" [52, page 721 ]. In one sample, $50 \%$ of obese boys and $58 \%$ of obese girls report experiencing significant problems with peers [46]. Obese children are almost twice as likely to be the victim of peer victimization, with girls more often reporting relational issues and boys reporting overt issues as both the victim and the perpetrator $[10,52,53]$. Being teased about weight is predictive of binge eating among adolescents [54] and is cross-sectionally associated with higher levels of disordered eating [55]. In addition to triggering body dissatisfaction and disordered eating, weight-based teasing has been linked to suicide attempts [23], implicated as a predictor of depressive symptoms [50], positively associated with anxiety, loneliness, social isolation, and parent reports of internalizing and externalizing behaviour problems [56] and experiences of shame [57] and negatively associated with physical activity [56].

6.2. Concern about Weight and Shape. A number of recent studies indicate that perceived overweight or concern about weight, rather than actual weight status, is predictive of the psychosocial/emotional fall-out of overweight/obesity [58]. Erickson et al. [59] were the first researchers to examine weight status and concern about weight and shape in relation to psychological outcomes. They found that, in a sample of 8 -year-old girls, those with high weight and shape concern experienced more depressive symptoms than those with low levels of weight concern, regardless of weight status. Since then a number of other researchers have investigated the role of weight and shape concerns. In a sample of 7- to 13-year-old boys and girls, Allen et al. [20] found that (a) overweight children were more concerned about weight and shape than were healthy weight children and (b) regardless of weight status, children with high weight and shape concern reported lower levels of self-esteem and higher levels of body dissatisfaction and depression than children with low weight and shape concern. More recently, Jansen et al. [21] explored the idea that "feeling fat" may be more important than "being fat" in terms of the psychological well-being of 12 and 13 year olds. In a representative German sample of over 17000 children and youth, obese children who considered their body weight "just right" perceived a higher quality of life than normal weight children who considered themselves "far too fat" [60]. Cumulatively, these results suggest that weight 
and shape concern rather than weight itself can account for differences in the psychological consequences of childhood overweight/obesity.

6.3. Summary. Existing studies can be used to speculate about relationships and links between factors. For example, teasing about weight in childhood may be related to emotional suffering, but at this point the direction of the relationship remains untested empirically. So while there is a level of confidence in the psychosocial factors, mediating variables and wellness factors presented in the model, the relationships between these variables are not clearly articulated through an examination of the literature. Further research through causal modeling or path analyses will help elucidate the relationships between the variables taken up in this paper.

\section{Obesity Impact on Wellness/Wellness Impact on Obesity}

In relation to obesity, much is known about healthy lifestyle (i.e., nutrition and physical activity), but little is known about well-being [13]. In fact, many of the recommendations for the treatment of child and adolescent overweight and obesity focus on physical outcomes like BMI and body composition with disregard for their impact on psychological or social well-being.

7.1. Quality of Life. Given that the psychosocial health of obese and overweight children and youth has been studied from a largely psychopathological perspective, measures often report on specific issues (i.e., depression and behavioural concerns). However, this approach fails to recognize or capture the limitations of well-being that may not meet specific diagnostic criteria. Emerging literature on quality of life (QOL) is beginning to fill this gap. "Quality of life can be defined as a multidimensional construct that reflects one's self-perceptions of enjoyment and satisfaction with life" [61, page 407]. Overweight children have reported lower QOL than non-overweight peers [51]. Studies suggest that the lower QOL for overweight children is related to physical functioning and psychosocial domains $[62,63]$, still obese children when compared to healthy-weight children are up to five times more likely to report lower global health-related QOL scores and in one study could not be distinguished in terms of scores from children with cancer receiving chemotherapy [31]. Some studies even indicated that differential QOL perceptions for children vary in the degree to which children are overweight [61]. Clinical samples show a stronger and more consistent association between overweight and lower QOL than population-based samples [64].

\section{Resilience}

Young people who show resilience have been found to have access to protective factors in three broad areas: (a) within themselves, (b) in their families, and (c) within the communities in which they live [65]. Resilience is defined as "the process of coping with adversity, change, or opportunity in a manner that results in the identification, fortification, and enrichment of resilient qualities or protective factors" [66, page 308]; it is a complex phenomenon that focuses on protective factors that contribute to positive outcomes despite the presence of risk $[67,68]$. Certainly in the context of our obesogenic and fat-phobic culture, obese and overweight children that are able to thrive and excel in spite of their current context would help us understand the concept of resiliency. Unfortunately, these questions have not been taken up in the literature to date. More research is needed to determine the reasons for resilience in children that are overweight or obese [69].

While traditional methods to enhance the health and well-being of young people have utilized a problem-focused paradigm, a focus on QOL and resilience provides opportunity to view childhood obesity and overweight through a lens of positive mental health and development. "In the absence of consensus about the causal pathways leading to the obesity epidemic, it is hard to devise a public health response that can affect its course" [70, page 40]. Public health can support the creation of solutions that do not further marginalize overweight and obese children and youth [69] and that can potentially improve the lives of all children and youth regardless of weight status.

\section{Stop the Focus on Weight}

Healthy lifestyle behaviours are important for the whole population regardless of weight status; weight is not a behaviour and therefore should not be an object of behaviour modification [71]. The discourse engendered by a focus on weight could increase psychological discontent for children/youth who struggle with body issues or eating problems by encouraging unhealthy self-monitoring [72] or unhealthy weight control practices. QOL shows potential as an outcome measure to quantify the impact of overweight/obesity on overall functioning and as a tool for planning appropriate interventions and protocols [51] that considers the "whole" child, as well as the health and wellness of all children, regardless of weight status. Rather than viewing overweight/obesity as a medical issue, reducing the incidence of overweight/obesity must be seen as a public health matter that is the shared responsibility of public, government, and corporate entities [73]. The focus on weight is a well-traveled but ineffective and unproductive path mired in excess focus on personal responsibility. A shift to weight-neutral outcomes has shown evidence of success in randomized control trials (see Bacon and Aphramor [74] for a review). Significant improvements in physiological measures, health behaviours, and psychosocial outcomes (like self-esteem and body image) have been found to result from approaches that focus on weight-neutral rather than weight-loss goals [74].

\section{Intervene with Weight Bias}

Weight bias is prevalent and being stigmatized triggers a maladaptive cycle of poor mental and physical health, which 
compromise uptake of the health behaviours necessary for the prevention of obesity and overweight. Recommendations to include weight bias awareness in the field of obesity, particularly obesity prevention efforts, have been largely ignored [75]. Health promotion experts have a unique opportunity to build psychosocial resilience among individuals and communities in an effort to reduce or prevent weight-related disorders. Individual factors are often the focus in childhood obesity literature, so refocusing on healthy relationships (e.g., healthy communication, problem-solving) shifts the focus one step outside the sole responsibility of the person who may literally and figuratively carry extra weight. In many ways, obesity is a social justice issue [76] and focusing on the relationship and contextual factors offers opportunities for intervention outside of the individual. Without consideration of weight-related issues as socially constructed and maintained, intervention efforts will likely fall short because it seeks to foster change from within the system rather than transforming the system that created the problems in the first place [77].

\section{Promote Healthy Body Image}

It is possible that the very public health strategies designed to combat the obesity epidemic may in fact engender the type of dialogue and environment that contribute to its development. Overweight children are even more concerned about weight than their normal-weight counterparts and even normal-weight children with high weight and shape concern report higher body dissatisfaction and depressive symptoms [20]. "It is critical that the possible iatrogenic impacts of health promotion messages are considered so that interventions do not trigger body image problems among target populations" [78, page 190]. A focus on early identification and prevention of weight and shape concern could reduce negative psychological outcomes for children of all weight statuses [20].

\section{Target Adult Role Models}

A number of recent documents suggest that a public health response to childhood obesity should include intervention across multiple sectors $[78,79]$. Parents and teachers are important role models for influencing children's attitudes and behaviours towards their bodies. Unfortunately, parental antifat bias [80] and focus on the importance of physical appearance [81] contribute to increased weight-bias attitudes in children. Similarly, teachers, attitudes towards weight, particularly towards obesity, may have harmful effects on children's emerging body image [54]. Common schoolbased practices such as discussing "healthy" weights without consideration of diversity, weighing students, displaying children's weights, discussing "healthy" eating [82], and reading literature with negative weight-bias and thin-ideal messages [83] have the often unrecognized potential for contributing to body dissatisfaction, weight bias, disordered eating, harmful peer comparisons regarding body size, and weight-related teasing. Thus, shifting focus from weight and shape to models of health, wellness, and resilience is critical to enhance the well-being of children and adolescents, regardless of weight status [84].

\section{Expand the Focus of Research}

Perhaps instead of comparative studies that examine obese versus nonobese populations, researchers should seek an understanding of what factors put some obese people at risk or, even better, what protective factors explain why some overweight/obese people are psychologically healthy in an obesogenic environment [85]. There is an absence of any systematic research on psychosocially and physically healthy overweight/obese individuals [69], in part because the idea that overweight or obesity may be that a rational, freely chosen, or rewarding personal attribute is just not considered [86] and the assumption continues that overweight/obese people are by definition unhealthy. The focus on resiliency and wellness in research on childhood obesity is in its infancy. In one of the only studies to approach childhood obesity from an asset model, Fenton et al. [78] found positive associations between healthy body image in adolescence and three variables, (a) ease of communication with parents, (b) teacher interested in students as people, and (c) feeling intelligent, and two demographic indicators (a) perceived family affluence and (b) household composition (presence of father figure in home). Indeed identifying the mechanisms that protect psychological well-being as well as targeting potential mediators to assess importance and relationships between mechanisms [13] is an important call to action for the research community.

\section{Conclusion}

"Systematic action and shared responsibility are necessary foundations on which to develop effective policies that support optimal child health and well-being" [87, page 199]. The emergence of social ecological models for understanding obesity is useful for considering the range of influences that contribute to obesity [88]. This paper focused primarily on one facet of influence, namely, mental health and wellness, which is arguably one of the most neglected areas of study in our understanding of childhood overweight/obesity. However, it must be noted that the complexity is not adequately accounted for in this paper. Nonetheless, intervening for the psychosocial emotional health of overweight/obese children should be a focus in and of itself and not just an "addon" measure to a primary outcome that is targeting weight reduction or the cessation of weight gain. Public health policy in the area of childhood obesity needs to encourage healthy body image, advocate that healthy behaviours come in every shape and size, and consider weight bias and weight and shape concerns as fundamental. In terms of mental health and wellness, this type of shift in paradigm could benefit all children and youth potentially for generations to come.

\section{Acknowledgments}

This paper is based on a literature review developed in response to a call issued by the Public Health Agency of 
Canada (PHAC). The authors wish to acknowledge PHAC for their support of this literature review.

\section{References}

[1] World Health Organization, "Health topics: Obesity," 2000, http://www.who.int/topics/obesity/en/.

[2] Statistics Canada, "Body mass index (BMI) for children and youth 2007 to 2009," 2000, http://www.statcan.gc.ca/ pub/82-625-x/2010001/.

[3] M. Shields, "Measured obesity: Overweight Canadian children and adolescents. Nutrition: Findings from the Canadian Community Health Survey," 2005, http://www.statcan.gc.ca.

[4] R. S. Strauss, "Childhood obesity and self-esteem," Pediatrics, vol. 105, no. 1, p. e15, 2000.

[5] P. M. Canning, M. L. Courage, and L. M. Frizzell, "Prevalence of overweight and obesity in a provincial population of Canadian preschool children," Canadian Medical Association Journal, vol. 171, no. 3, pp. 240-242, 2004.

[6] M. S. Tremblay and J. D. Willms, "Secular trends in the body mass index of Canadian children," Canadian Medical Association Journal, vol. 163, no. 11, pp. 1429-1433, 2000.

[7] D. Wilmms, M. S. Tremblay, and P. T. Katzmarzyk, "Geographic and demographic variation in the prevalence of overweight Canadian children," Obesity Research, vol. 11, no. 5, pp. 668-673, 2003.

[8] R. R. Friedman and M. B. Schwartz, "Public policy to prevent childhood obesity, and the role of pediatric endocrinologists," Journal of Pediatric Endocrinology and Metabolism, vol. 21, no. 8, pp. 717-725, 2008.

[9] E. Stice, K. Presnell, M. R. Lowe, and E. Burton, "Validity of dietary restraint scales: reply to van Strien et al. (2006)," Psychological Assessment, vol. 18, no. 1, pp. 95-99, 2006.

[10] R. E. Cornette, "The emotional impact of obesity on children," in Global Perspectives on Childhood Obesity: Current Status, Consequences and Prevention, D. Bagchi, Ed., pp. 257-264, Elsevier, New York, NY, USA, 2011.

[11] M. Vos and S. E. Barlow, "Update in childhood and adolescent obesity," Pediatric Clinics of North America, vol. 58, pp. 15-17, 2011.

[12] L. Y. Gibson, "An overview of psychosocial symptoms in obese children," in Global Perspectives on Childhood Obesity: Current Status, Consequences and Prevention, D. Bagchi, Ed., pp. 233 244, Elsevier, New York, NY, USA, 2011.

[13] J. Wardle and L. Cooke, "The impact obesity on psychological well-being," Clinical Endocrinology and Metabolism, vol. 19, no. 3, pp. 421-440, 2005.

[14] S. A. French, M. Story, and C. L. Perry, "Self-esteem and obesity in children and adolescents: a literature review," Obesity, vol. 3, no. 5, pp. 479-490, 1995.

[15] S. E. Anderson, P. Cohen, E. N. Naumova, and A. Must, "Association of depression and anxiety disorders with weight change in a prospective community-based study of children followed up into adulthood," Archives of Pediatrics \& Adolescent Medicine, vol. 160, no. 3, pp. 285-291, 2006.

[16] E. Goodman and R. C. Whitaker, "A prospective study of the role of depression in the development and persistence of adolescent obesity," Pediatrics, vol. 110, no. 3, pp. 497-504, 2002.

[17] E. Stice, K. Presnell, K. Shaw, and P. Rhode, "Psychological and behavioral risk factors for obesity onset in adolescent girls: a prospective study," Journal of Consulting and Clinical Psychology, vol. 73, no. 2, pp. 195-202, 2005.

[18] M. Tanofsky-Kraff, M. L. Cohen, S. Z. Yanovski et al., "A prospective study of psychological predictors of body fat gain among children at high risk for adult obesity," Pediatrics, vol. 117, no. 4, pp. 1203-1209, 2006.

[19] J. C. Lumeng, K. Gannon, H. J. Cabral, D. A. Frank, and B. Zuckerman, "Association between clinically meaningful behavior problems and overweight in children," Pediatrics, vol. 112, no. 5, pp. 1138-1145, 2003.

[20] K. L. Allen, S. M. Byrne, E. M. Blair, and E. A. Davis, "Why do some overweight children experience psychological problems? The role of weight and shape concern," International Journal of Pediatric Obesity, vol. 1, no. 4, pp. 239-247, 2006.

[21] W. Jansen, P. M. van de Looij-Jansen, E. J. de Wilde, and J. Brug, "Feeling fat rather than being fat may be associated with psychological well-being in young Dutch adolescents," Journal of Adolescent Health, vol. 42, no. 2, pp. 128-136, 2008.

[22] P. van den Berg and D. Neumark-Sztainer, "Fat n' happy 5 years later: is it bad for overweight girls to like their bodies?" Journal of Adolescent Health, vol. 41, no. 4, pp. 415-417, 2007.

[23] M. E. Eisenberg, D. Neumark-Sztainer, and M. Story, "Associations of weight-based teasing and emotional well-being among adolescents," Archives of Pediatrics \& Adolescent Medicine, vol. 157, no. 8, pp. 733-738, 2003.

[24] J. S. Rawana, A. S. Morgan, H. Nguyen, and S. G. Craig, "The relation between eating- and weight-related disturbances and depression in adolescence: a review," Clinical Child \& Family Psychology Review, vol. 13, no. 3, pp. 213-230, 2010.

[25] G. S. Goldfield, C. Moore, K. Henderson, A. Buchholz, N. Obeid, and M. F. Flament, "Body dissatisfaction, dietary restraint, depression, and weight status in adolescents," The Journal of School Health, vol. 80, no. 4, pp. 186-192, 2010.

[26] B. Britz, W. Siegfried, A. Ziegler et al., "Rates of psychiatric disorders in a clinical study group of adolescents with extreme obesity and in obese adolescents ascertained via a population based study," International Journal of Obesity and Related Metabolic Disorders, vol. 24, no. 12, pp. 1707-1714, 2000.

[27] M. Tanofsky-Kraff, S. Z. Yanovski, D. E. Wilfley, C. Marmarosh, C. M. Morgan, and J. A. Yanovski, "Eating-disordered behaviors, body fat, and psychopathology in overweight and normal-weight children," Journal of Consulting and Clinical Psychology, vol. 72, no. 1, pp. 53-61, 2004.

[28] A. J. Zametkin, C. K. Zoon, H. W. Klein, and S. Munson, "Psychiatric aspects of child and adolescent obesity: a review of the past 10 years," Journal of the American Academy of Child and Adolescent Psychiatry, vol. 43, no. 2, pp. 134-150, 2004.

[29] D. M. Ackard, D. Neumark-Sztainer, M. Story, and C. Perry, "Overeating among adolescents: prevalence and associations with weight-related characteristics and psychological health," Pediatrics, vol. 111, no. 1, pp. 67-74, 2003.

[30] C. Renman, I. Engström, S. A. Silfverdal, and J. Åman, "Mental health and psychosocial characteristics in adolescent obesity: a population-based case-control study," Acta Paediatrica, vol. 88, no. 9, pp. 998-1003, 1999.

[31] J. Schwimmer, T. Burwinkle, and J. Varni, "Health-related quality of life of severely obese children and adolescents," Journal of the American Medical Association, vol. 289, no. 14, pp. 1813-1819, 2003.

[32] J. A. O'Dea, “School-based health education strategies for the improvement of body image and prevention of eating problems: an overview of safe and successful interventions," Health Education, vol. 105, no. 1, pp. 11-33, 2005. 
[33] S. B. Austin, J. Haines, and P. J. Veugelers, "Body satisfaction and body weight: gender differences and sociodemographic determinants," BMC Public Health, vol. 9, article 313, 2009.

[34] M. Kostanski, A. Fisher, and E. Gullone, "Current conceptualisation of body image dissatisfaction: have we got it wrong?" The Journal of Child Psychology and Psychiatry, vol. 45, no. 7, pp. 1317-1325, 2004.

[35] A. E. Field, S. B. Austin, C. B. Taylor et al., "Relation between dieting and weight change among preadolescents and adolescents," Pediatrics, vol. 112, no. 4, pp. 900-906, 2003.

[36] M. Tanofsky-Kraff, S. Z. Yanovski, N. A. Schvey, C. H. Olsen, J. Gustafson, and J. A. Yanovski, "A prospective study of loss of control eating for body weight gain in children at high risk for adult obesity," International Journal of Eating Disorders, vol. 42, no. 1, pp. 26-30, 2009.

[37] D. Neumark-Sztainer, M. Story, P. J. Hannan, C. L. Perry, and L. M. Irving, "Weight-related concerns and behaviors among overweight and nonoverweight adolescents: implications for preventing weight-related disorders," Archives of Pediatrics and Adolescent Medicine, vol. 156, no. 2, pp. 171-178, 2002.

[38] E. Stice, K. Presnell, L. Groesz, and H. Shaw, "Effects of a weight maintenance diet on bulimic symptoms in adolescent girls: an experimental test of the dietary restraint theory," Health Psychology, vol. 24, no. 4, pp. 402-412, 2005.

[39] F. Johnson and J. Wardle, "Dietary restraint, body dissatisfaction, and psychological distress: a prospective analysis," Journal of Abnormal Psychology, vol. 114, no. 1, pp. 119-125, 2005.

[40] L. Claus, C. Braet, and V. Decaluwé, "Dieting history in obese youngsters with and without disordered eating," International Journal of Eating Disorders, vol. 39, no. 8, pp. 721-728, 2006.

[41] E. Stice and H. A. Shaw, "Role of body dissatisfaction in the onset and maintenance of eating pathology: a synthesis of research findings," Journal of Psychosomatic Research, vol. 53, no. 5, pp. 985-993, 2002.

[42] G. Lundstedt, B. Edlund, I. Engström, B. Thurfjell, and C. Marcus, "Eating disorder traits in obese children and adolescents," Eating and Weight Disorders, vol. 11, no. 1, pp. 45-50, 2006.

[43] V. Decaluwé and C. Braet, "Prevalence of binge-eating disorder in obese children and adolescents seeking weight-loss treatment," International Journal of Obesity, vol. 27, no. 3, pp. 404-409, 2003.

[44] V. Decaluwé, C. Braet, and C. G. Fairburn, "Binge eating in obese children and adolescents," International Journal of Eating Disorders, vol. 33, no. 1, pp. 78-84, 2003.

[45] R. Cornette, "The emotional impact of obesity on children," Worldviews on Evidence-Based Nursing, vol. 5, no. 3, pp. 136141, 2008.

[46] P. Warschburger, "The unhappy obese child," International Journal of Obesity, vol. 29, no. 2, pp. S127-S129, 2005.

[47] J. D. Latner and A. J. Stunkard, "Getting worse: the stigmatization of obese children," Obesity Research, vol. 11, no. 3, pp. 452-456, 2003.

[48] J. W. Hwang, I. K. Lyoo, B. N. Kim, M. S. Shin, S. J. Kim, and S. C. Cho, "The relationship between temperament and character and psychopathology in community children with overweight," Journal of Developmental \& Behavioral Pediatrics, vol. 27, no. 1, pp. 18-24, 2006.

[49] R. M. Puhl and J. D. Latner, "Stigma, obesity, and the health of the nation's children," Psychological Bulletin, vol. 133, no. 4, pp. 557-580, 2007.
[50] R. E. Adams and W. M. Bukowski, "Peer victimization as a predictor of depression and body mass index in obese and non-obese adolescents," Journal of Child Psychology \& Psychiatry, vol. 49, no. 8, pp. 858-866, 2008.

[51] D. M. Janicke, K. K. Marciel, L. M. Ingerski et al., "Impact of psychosocial factors on quality of life in overweight youth," Obesity, vol. 15, no. 7, pp. 1799-1807, 2007.

[52] W. N. Gray, N. A. Kahhan, and D. M. Janicke, "Peer victimization and pediatric obesity: a review of the literature," Psychology in The Schools, vol. 46, no. 8, pp. 720-727, 2009.

[53] S. Robinson, "Victimization of obese adolescents," The Journal of School Nursing, vol. 22, no. 4, pp. 201-206, 2006.

[54] J. Haines and D. Neumark-Sztainer, "Prevention of obesity and eating disorders: a consideration of shared risk factors," Health Education Research, vol. 21, no. 6, pp. 770-782, 2006.

[55] D. Neumark-Sztainer, N. Falkner, M. Story, C. Perry, P. J. Hannan, and S. Mulert, "Weight-teasing among adolescents: correlations with weight status and disordered eating behaviors," International Journal of Obesity, vol. 26, no. 1, pp. 123131, 2002.

[56] E. A. Storch, V. A. Milsom, N. DeBraganza, A. B. Lewin, G. R. Geffken, and J. H. Silverstein, "Peer victimization, psychosocial adjustment, and physical activity in overweight and atrisk-for-overweight youth," Journal of Pediatric Psychology, vol. 32, no. 1, pp. 80-89, 2007.

[57] R. L. Sjöberg, K. W. Nilsson, and J. Leppert, "Obesity, shame, and depression in school-aged children: a population-based study," Pediatrics, vol. 116, no. 3, pp. e389-e392, 2005.

[58] E. M. Perrin, J. Boone-Heinonen, A. E. Field, T. CoyneBeasley, and P. Gordon-Larsen, "Perception of overweight and self-esteem during adolescence," International Journal of Eating Disorders, vol. 43, no. 5, pp. 447-454, 2010.

[59] S. J. Erickson, T. N. Robinson, K. F. Haydel, and J. D. Killen, "Are overweight children unhappy? Body mass index, depressive symptoms, and overweight concerns in elementary school children," Archives of Pediatrics and Adolescent Medicine, vol. 154, no. 9, pp. 931-935, 2000.

[60] B.-M. Kurth and U. Ellert, "Perceived or true obesity: which causes more suffering in adolescents?-findings of the German health interview and examination survey for children and adolescents (KiGGS)," Deutsches Arzteblatt International, vol. 105, no. 23, pp. 406-412, 2008.

[61] J. A. Shoup, M. Gattshall, P. Dandamudi, and P. Estabrooks, "Physical activity, quality of life, and weight status in overweight children," Quality of Life Research, vol. 17, no. 3, pp. 407-412, 2008.

[62] S. L. Friedlander, E. K. Larkin, C. L. Rosen, T. M. Palermo, and S. Redline, "Decreased quality of life associated with obesity in school-aged children," Archives of Pediatrics and Adolescent Medicine, vol. 157, no. 12, pp. 1206-1211, 2003.

[63] O. Pinhas-Hamiel, S. Singer, N. Pilpel, A. Fradkin, D. Modan, and B. Reichman, "Health-related quality of life among children and adolescents: associations with obesity," International Journal of Obesity, vol. 30, no. 2, pp. 267-272, 2006.

[64] K. C. Swallen, E. N. Reither, S. A. Haas, and A. M. Meier, "Overweight, obesity, and health-related quality of life among adolescents: the national longitudinal study of adolescent health," Pediatrics, vol. 115, no. 2, pp. 340-347, 2005.

[65] M. Place, J. Reynold, A. Cousins, and S. O’Neill, "Developing a resilience package for vulnerable children," Child Adolescent Mental Health, vol. 7, no. 4, pp. 162-167, 2002.

[66] G. E. Richardson, "The metatheory of resilience and resiliency," Journal of Clinical Psychology, vol. 58, no. 3, pp. 307321, 2002. 
[67] R. J. Dent and R. J. S. Cameron, "Developing resilience in children who are in public care: the educational psychology perspective," Educational Psychology in Practice, vol. 19, no. 1, pp. 3-19, 2003.

[68] A. D. Mancini and G. A. Bonanno, "Resilience in the face of potential trauma: clinical practices and illustrations," Journal of Clinical Psychology, vol. 62, no. 8, pp. 971-985, 2006.

[69] P. V. Bromfield, "Childhood obesity: psychosocial outcomes and the role of weight bias and stigma," Educational Psychology in Practice, vol. 25, no. 3, pp. 193-209, 2009.

[70] W. Maziak, K. D. Ward, and M. B. Stockton, "Childhood obesity: are we missing the big picture?" Obesity Reviews, vol. 9, no. 1, pp. 35-42, 2008.

[71] S. Daníelsdóttir, D. Burgard, and W. Oliver-Pyatt, AED Guidelines for Childhood Obesity Prevention Programs, http://www.aedweb.org/AM/Template.cfm?Section=Advocacy \&Template $=/ C M /$ ContentDisplay.cfm\&ContentID $=1659$.

[72] J. Larkin and C. Rice, "Beyond "healthy eating" and "healthy weights": harassment and the health curriculum in middle schools," Body Image, vol. 2, no. 3, pp. 219-232, 2005.

[73] K. D. Brownell, M. B. Schwartz, R. M. Puhl, K. E. Henderson, and J. L. Harris, "The need for bold action to prevent adolescent obesity," Journal of Adolescent Health, vol. 45, no. 3, supplement, pp. S8-S17, 2009.

[74] L. Bacon and L. Aphramor, "Weight science: evaluating the evidence for a paradigm shift," Nutrition Journal, vol. 10, article 9, 2011.

[75] R. M. Puhl and C. A. Heuer, "Obesity stigma: important considerations for public health," American Journal of Public Health, vol. 100, no. 6, pp. 1019-1028, 2010.

[76] S. Russell-Mayhew, "Eating disorders and obesity as social justice issues: implications for research and practice," Journal for Social Action in Counseling and Psychology, vol. 1, no. 1, pp. $1-13,2007$.

[77] S. L. Speight and E. M. Vera, "A social justice agenda: ready, or not?” The Counseling Psychologist, vol. 32, no. 1, pp. 109-118, 2004.

[78] C. Fenton, F. Brooks, N. H. Spencer, and A. Morgan, "Sustaining a positive body image in adolescence: an assets-based analysis," Health \& Social Care in The Community, vol. 18, no. 2, pp. 189-198, 2010.

[79] Public Health Agency of Canada, "Curbing childhood obesity: A federal, provincial and territorial framework for action to promote healthy weights," 2010, http://www.phac-aspc .gc.ca/hp-ps/hl-mvs/framework-cadre/pdf/ccofw-eng.pdf.

[80] K. K. Davison and L. L. Birch, "Predictors of fat stereotypes among 9-year-old girls and their parents," Obesity Research, vol. 12, no. 1, pp. 86-94, 2004.

[81] C. Davis, B. Shuster, E. Blackmore, and J. Fox, "Looking good: family focus on appearance and the risk for eating disorders," International Journal of Eating Disorders, vol. 35, no. 2, pp. 136-144, 2004.

[82] G. McVey, J. Gusella, S. Tweed, and M. Ferrari, "A controlled evaluation of web-based training for teachers and public health practitioners on the prevention of eating disorders," Eating Disorders, vol. 17, no. 1, pp. 1-26, 2009.

[83] M. M. Glessner, J. H. Hoover, and L. A. Hazlett, "The portrayal of overweight in adolescent fiction. Reclaiming children and youth," The Journal of Strength-Based Interventions, vol. 15, no. 2, pp. 116-123, 2006.

[84] J. A. Fulkerson, J. Strauss, D. Neumark-Sztainer, M. Story, and K. Boutelle, "Correlates of psychosocial well-being among overweight adolescents: the role of the family," Journal of
Consulting and Clinical Psychology, vol. 75, no. 1, pp. 181-186, 2007.

[85] L. Walker and A. J. Hill, "Obesity: the role of child mental health services," Child \& Adolescent Mental Health, vol. 14, no. 3, pp. 114-120, 2009.

[86] J. Evans, R. Evans, C. Evans, and J. E. Evans, "Fat free schooling: the discursive production of ill-health," International Studies in The Sociology of Education, vol. 12, no. 2, pp. 191212, 2002.

[87] N. Reynolds, "Commentary on child health and wellbeing...the policy-research interface," Canadian Journal of Occupational Therapy, vol. 76, pp. 199-205, 2009.

[88] L. A. Lytle, "Examining the etiology of childhood obesity: the idea study," American Journal of Community Psychology, vol. 44, no. 3-4, pp. 338-349, 2009. 


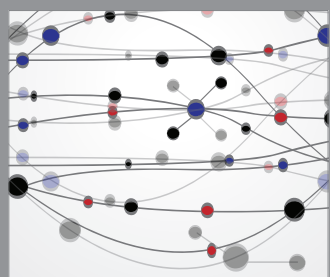

The Scientific World Journal
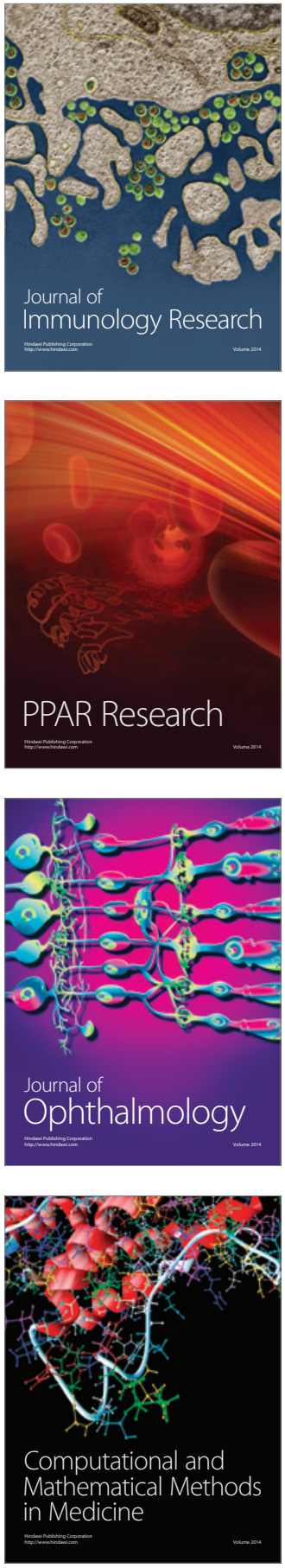

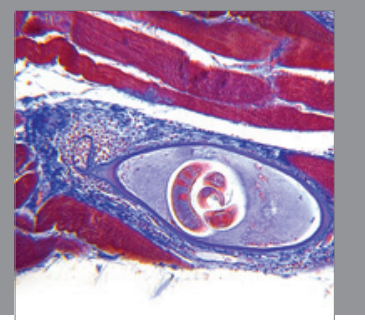

Gastroenterology

Research and Practice
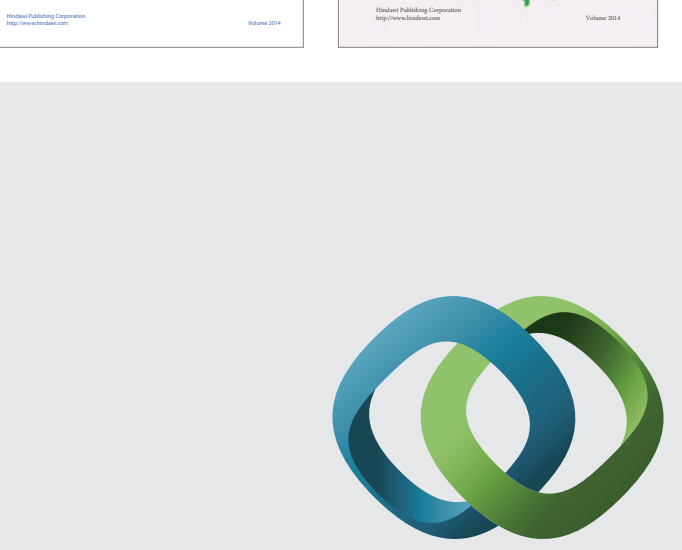

\section{Hindawi}

Submit your manuscripts at

http://www.hindawi.com
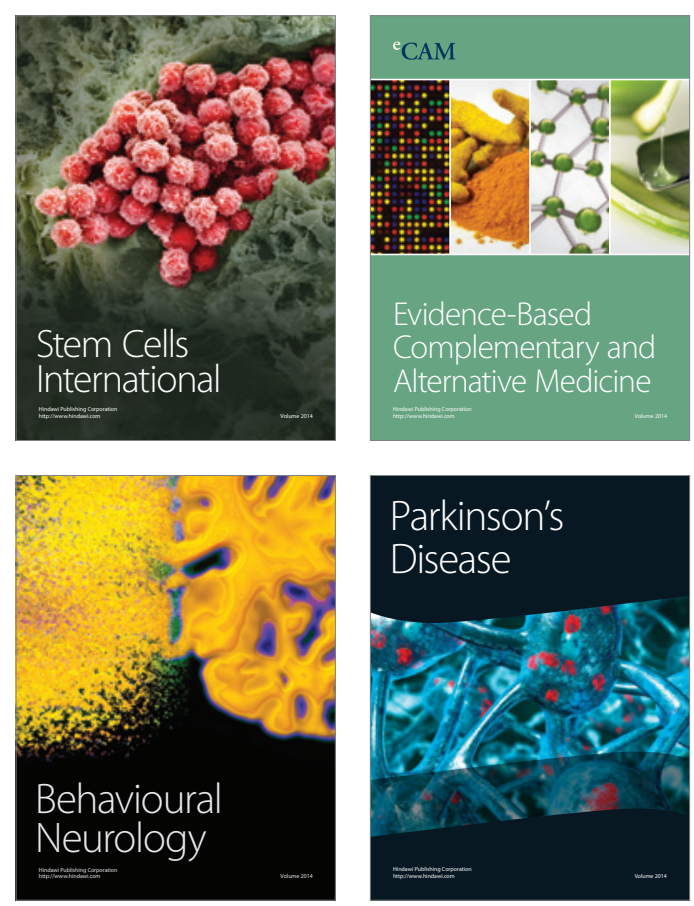

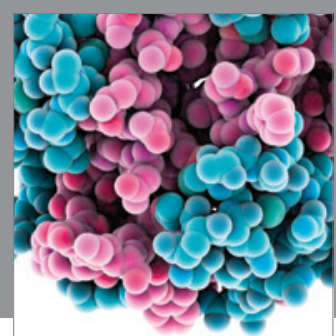

Journal of
Diabetes Research

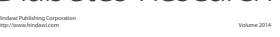

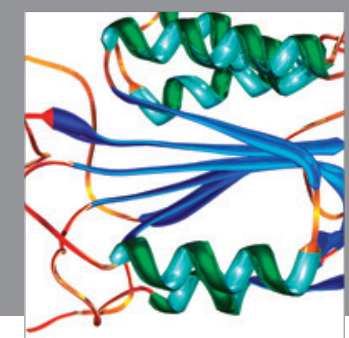

Disease Markers
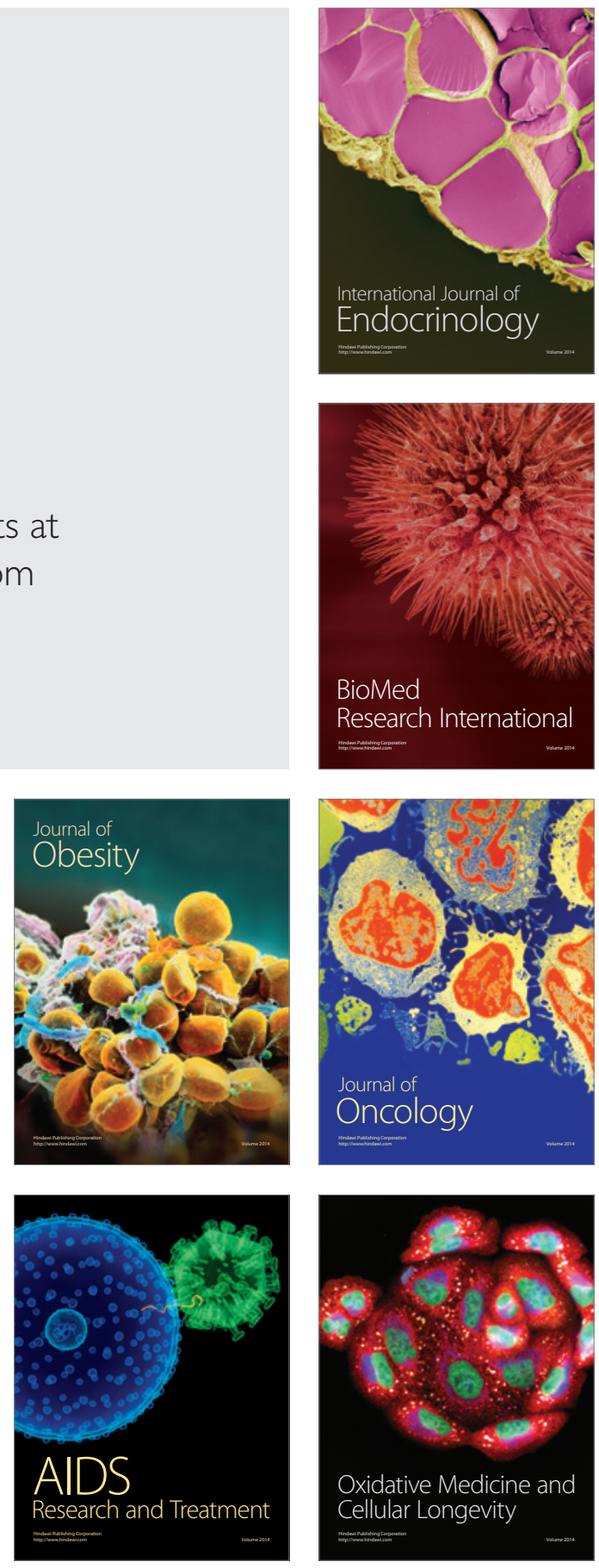